\title{
Effect of Swiss Ball on Balance in Children with Spastic Diplegia: A Case Study
}

\author{
Shahanawaz SD ${ }^{1}$, Tushar.J.Palekar ${ }^{2}$, Nidhi Shah ${ }^{3}$ \\ ${ }^{1}$ PhD Scholar and Assistant Professor, Dr.D.Y.Patil College of Physiotherapy, Dr.D.Y.Patil \\ Vidyapeeth (Deemed University), Pune \\ shanu.neuropt@gmail.com \\ ${ }^{2}$ Professor and Principal, Dr.D.Y.Patil College of Physiotherapy, Dr.D.Y.Patil Vidyapeeth \\ (Deemed University), Pune \\ ${ }^{3}$ MPT Pediatrics I year Student, Dr.D.Y.Patil College of Physiotherapy,Dr.D.Y.Patil Vidyapeeth \\ (Deemed University), Pune
}

\begin{abstract}
:
Introduction: Cerebral Palsy (CP) is a neuromuscular dysfunction caused by lesions in the brain that occur before birth or in prenatal stages (McGee \& Reese, 2009; McGibbon, Andrade, Widener, \& Cintas, 1998; Sterba, 2007).

Vestibular system is one of the main structure to maintain balance, as it serves as an absolute reference in relation to the others, such as visual and somato sensorial systems. ${ }^{1}$ Sufficiently administered vestibular stimulation has been reported to improve balance, the vestibular-spinal reflex generates body motion compensation, to maintain head and postural stability and alignment, and thus preventing falls. ${ }^{13}$
\end{abstract}

Purpose of study: Literature has evidences favouring vestibular stimulation on balance in children with infantile hemiplegia, down syndrome etc. Responses obtained from stimulation of vestibular system facilitate muscles which help to evoke movements of head, trunk and limbs to compensate for postural sway. ${ }^{3}$ There are various equipments used for vestibular stimulation like trampoline, scooter boards, hammock swing, swiss ball etc. ${ }^{\text {T }}$ Though, literature has mentioned about the use of sensory integration therapy (including vestibular stimulation) on gross motor skills in spastic diplegic cerebral palsy ${ }^{4}$.

The cerebellum along with input from the vestibular system provides balance, orientation in space\& coordination ${ }^{4}$.

Swiss ball can be used as a treatment to train balance equilibrium and righting reactions along with providing strengthening exercises and Proprioceptive training. ${ }^{5}$

Thus the study aims to study the effectiveness of vestibular stimulation on balance using Swiss ball in children with spastic diplegia.

Aim of the study: To know the effect of vestibular stimulation on balance in children with spastic diplegia.

Methodology: A diagnosed cerebral palsy male child whose age was 5 years. He was evaluated based on GMFCS level IV, and also evaluated on GMFM 88 score. Physical therapy treatment was given for 8 sessions /week for 4 weeks.

Conclusion: The study was analysed on gross motor components which shows improvement in the Measured by using the GMFM-88

\section{INTRODUCTION}

Cerebral Palsy (CP) is a neuromuscular dysfunction caused by lesions in the brain that Occur before birth or in prenatal stages (McGee \& Reese, 2009; McGibbon, Andrade, Widener, \& Cintas, 1998; Sterba, 2007). As a result, children with CP lack normal muscle tone, which effects control of limbs, head, and overall posture (Bertoti, 1988; Casady, \& Nichols-Larson, 2004; McGibbon, Benda, Duncan, \& Silkwood-Sherer, 2009).

According to Indian academy of Cerebral Palsy(IACP) incidence of CP is 2-2.5 cases per 1000 live births in India and spastic diplegia is the commonest form 30\%-40\%, hemiplegia is $20 \%-30 \%$, and quadriplegia accounting for $10 \%-15 \%$. In an analysis of 1000 cases of CP from India, Singhi PD et al found that spastic diplegia constituted $22 \% .^{2}$ 
The large majority of children with CP have difficulty in walking, demonstrate poor balance control: that leads to poor gait and reaching movement as the maintenance of stability is critical to all movements. ${ }^{1}$

Vestibular system is one of the main structure to maintain balance, as it serves as an absolute reference in relation to the others, such as visual and somato sensorial systems. ${ }^{1}$ Sufficiently administered vestibular stimulation has been reported to improve balance, the vestibular-spinal reflex generates body motion compensation, to maintain head and postural stability and alignment, and thus preventing falls. ${ }^{13}$

\section{Purpose of The Study}

The purpose of this case study was to explore the effects of swiss ball therapy on one child, who has spastic diplegic CP . Researchers propose that swiss ball therapy may improve balance, posture, mobility, and function (Kwon et al., 2011; Sterba, 2007; Violette \&Wilmarth, 2009). The effects of swiss ball therapy on a child with CP was defined as changes in head and neck control, trunk alignment, extremity function, and muscle tone.

Swiss ball therapy therapy method utilized to solve the general research problem that children with $\mathrm{CP}$ have impaired posture, balance, mobility, and function due to atypical muscle tone (Kwon et al., 2011; Sterba, 2007; Violette \&Wilmarth, 2009).

Aim:

To know the effect of vestibular stimulation on balance in children with spastic diplegia.

\section{Objectives:}

1. To measure pre treatment and post treatment GMFM score..

2. To analyse the effect of vestibular stimulation exercises on balance in children with spastic diplegia.

\section{Materials AND Methodology}

McGibbon suggests that a case study is Beneficial because subjects are able to serve as their own control, and case studies are useful, when evaluating a person with a unique or rare case (1998),

Before the research study, the mother of the chosen child was addressed about her child's participation in the study and consent was documented. In addition, for ethical purposes, the child was addressed by his first name, Sudharshan, rather than his full birth name. As this study only evaluated one child, the case study child did not represent the population and the results only pertained to the child being observed

In order to investigate the effects of swiss ball therapy on a child with spastic $\mathrm{CP}$, a qualitative case study was conducted. A diagnosed cerebral palsy with age of 5 years came to the physiotherapy department for the treatment, the past history of the child shows that at 5 months attack lead to lack of oxygen to brain occurred, and his mother belives this was the onset of CP, At this the time the child was placed ventilator for a period of 1 to 2 weeks, and at age one and a half, Sudharshan was diagnosed with spastic diplegic CP. His mother noticed abnormalities in Sudharshan's development and also observed that he is not performing any kicking movements and increased in the muscle tone, Additionally, sudharshan had asymmetrical tonic neck reflex (ATNR) which negatively affects his head and arm ability. After receiving the background information, The child was evaluated by using Gross Motor Functional Classification System (GMFCS ) with a level IV and also evaluated with GMFM-88 scoring the pre score shows 62 ,GMFM - 88 scoring and Paediatric balance scale will be taken prior to therapy in both the groups. The Vestibular stimulation exercises using Swiss ball would be bouncing up \& down: 10 mins, to and fro: 10 mins and spinning for 10 mins. Post treatment scores will be taken. Readings will be noted down.

Duration for intervention: 5 days per week for 4 weeks. ${ }^{4,8,12,14}$

\section{DisCUSSION}

Firstly, 20 session of therapy was given to child on the swiss ball therapy .It was also observed that because of the more number of cerebral palsy childs also given the physical therapy treatment 
firmness or hardness of ball reduces, Consequentially, the swiss ball therapy had to be changed two eight sessions before the results ..ATNR significantly inhibits sudharshans's extremity function. However, while swisss ball therapy, Sudharshan demonstrated a decreased influence of ATNR. The therapist would help sudharshan's turn his head to the left to address the ATNR that affected the right side of his body. During the twentyth session, it was noted that when sudharshan crossed the midline with his upper extremities, ATNR became engaged limiting the functional use of his hands

Cherng Rong Ju et $\mathrm{al}^{7}$ in August,1999 which aimed to investigate and compare the static standing balance under altered sensory environments in children with spastic diplegia. 14 children were selected of which seven were spastic diplegics and 7 were age and gender matched non-disabled children. Thus, the study concluded that the children with spastic diplegic cerebral palsy may have difficulties in resolving intersensory conflicts for maintenance of standing balance.

\section{ReSUltS}

The Vestibular stimulation exercises using Swiss ball would be bouncing up \& down: 10 mins, to and fro: 10 mins and spinning for 10 mins. Duration for intervention: 5 days per week for 4 weeks.t was measured on GMFM -88 Score where it was observed that pre score was 62 and post score after 4weeks was 110.

\section{Conclusion}

This research study was conducted to investigate how swiss ball therapy affects a child with spastic diplegia cerebral palsy. The possible areas of swiss ball therapy could improve include head and neck control, trunk alignment, extremity function, and muscle tone (Kwon et al., 2011; Sterba, 2007; Violette \&Wilmarth, 2009). Therefore, the general problem was d analyzed in GMFM-88 where obtained pre score was 62 and after 4 weeks the post score after 4 weeks was 110 . Swiss ball therapy improved head and neck control, trunk alignment, extremity function, and abnormal muscle tone for Sudharshan, the case study child.

Results from this research study pertained only to the case study child, sudharshan, and thus, the effects of swiss ball therapy on $\mathrm{CP}$ could not be generalized but only suggested to others with $\mathrm{CP}$

Consequently, the goal of this case study was to corroborate past research and provide recommendations for future research that could eventually generalize the effects of swiss ball therapy on children with $\mathrm{CP}$

\section{REFERENCES}

[1]. Cook Shumway; Woollacott M; Motor control: theory and application 2005(2);72-74;132

[2]. Singhi PD, Ray M, Suri G. Clinical Spectrum of Cerebral Palsy in North India-An Analysis of 1000 Cases. J Trop Pediatr 2002; 48: 162-166.

[3]. Fischer A G; Murray E A \& Bundy A C; Sensory integration: theory and practice, 1991; Philadelphia; F..A.Davis \& Co.

[4]. Ayres AJ;Sensory integration and learning disorders ,1972; Los Angeles: Western Psychological Service

[5]. Carriere B; The Swiss Ball; Theory ,Basic exercise and clinical application;1998 Nov; (1)11, 321-322

[6]. Kantner RM, Clark DL,Allen LC,Chase MF; Effects of vestibular stimulation on nystagmus response and motor performance in the developmentally delayed infant : Phys Ther 1976 Apr;56(4):414-21

[7]. Cherng, Rong-Ju MA ; Su, Fong-Chin ; Chen, Jia-Jin Jason ; Kuan, Ta-Shen; Performance of static standing balance in children with spastic diplegic cerebral palsy under altered sensory environments: American Journal of Physical Medicine \& Rehabilitation: July/August 1999 Volume 78 - Issue 4 - pp 336-343

[8]. Medeiros, Italo R. T; Bittar, Roseli S. M; Pedalini, Maria Elisabete B; Lorenzi, Maria Cecília; Formigoni, Lázaro G; Bento, Ricardo F; Vestibular Rehabilitation Therapy in Children ; Otology \& Neurotology $2005 \mathrm{Jul}$; 26(4): 699-703 
[9]. Pavao SL Dos Santos AN, de Oliveira AB, Rocha NA; Functionality level and its relation to postural control during sitting-to-stand movement in children with cerebral palsy; ResDev Disabil. 2014 Feb;35(2):506-11

[10]. Iatridou G, Dionyssiotis Y; Reliability of balance evaluation in children with cerebral palsy. Hippokratia. 2013 Oct;17(4):303-6

[11].Franjoine MR, Gunther JS, Taylor MJ;Pediatric balance scale: a modified version of the berg balance scale for the school-age child with mild to moderate motor impairment Paediatr Phys Ther 2003 Summer;15(2):114-28.

[12]. Chettri Sabnam, Pattanaik Monalisa, Mohanty Patitapaban; Effect of vestibular stimulation on standing balance in spastic diplegic cerebral palsy; J. of Rehab; 2014 July ;1(1); 113-125.

[13]. Herdman S; Vestibular rehabilitation; Management of the paediatric patient with vestibular hypofunction;2008(3)360-375

[14]. Kenneth J; Sellick Ray ; Effects of Vestibular Stimulation on Motor Development of Cerebralpalsied Children; J.Developmental Medicine \& Child Neurology; Nov 2009(22) 4,476-483 